\title{
Estado e Capital: uma ineliminável relação de complementariedade à base material
}

Fernando de Araújo Bizerra
Universidade Federal de Alagoas (UFAL)

\author{
Juliana Carla da Silva Gois \\ Universidade Federal de Alagoas (UFAL)
}

Estado e Capital: uma ineliminável relação de complementariedade à base material

Resumo: Num movimento de contrafluxo às tendências dominantes na academia e nas Ciências Humanas, rotuladas principalmente pelo verniz pós-moderno, que apregoam a autonomia absoluta do Estado e, portanto, disseminam a possibilidade desse complexo se constituir como loci privilegiado para o fim das desigualdades sociais e para a conquista de uma sociedade verdadeiramente emancipada, este artigo traz à tona, a partir de Marx e de Mészáros, a relação de complementariedade exercida pelo Estado moderno no interior do sistema sóciometabólico do capital. Objetiva elucidar a função de complementação desempenhada pelo Estado fundamental ao sistema sociorreprodutivo do capital no que diz respeito à intervenção corretiva sobre os processos socioeconômicos. Entende que o Estado desempenha um papel complementar e inseparável do sistema do capital.

Palavras-chave: Estado. Capital. Relação de complementariedade.

State and Capital: an irremovable relation of complementarity to the material base

Abstract: This article takes a direction counter to the dominant academic trends and those in the human sciences in particular, labeled mainly by their post-modern varnish and that preach the absolute autonomy of the state, and therefore, disseminate the possibility of the state to establish itself as the privileged loci for the termination of social inequalities and for the conquest of a truly emancipated society. This article uses Marx and Mészáros to discuss the complementary relationship between the modern state and the sociometabolism of the capitalist system. The objective is to elucidate the complementary function of the state, which is essential to the socio-reproductive system of capital and the corrective intervention of socio-economic processes. It is understood that the state performs a complementary and inseparable role in the capitalist system.

Keywords: State. Capital. Relationship of complementarity. 


\section{Introdução}

O presente estudo nasce sob o crivo da polêmica teórica e política instaurada acerca do Estado e da sua relação com a base material. Tema presente nas mais diversas tendências teóricas das Ciências Sociais, o Estado é objeto de múltiplas interpretações que, imbuídas de um conteúdo teórico diversificado, ora o separa e o autonomiza da esfera econômica, ora apreende seus nexos ontológicos, ambas suscitando uma fecunda matriz teórica de análise. Considerando a importância que esse debate assumiu no decurso do século 20, sobretudo com as experiências revolucionárias que buscaram alavancar uma revolução socialista tendo como mediação principal o Estado, e ainda representa nos dias atuais, procuraremos, pois, demonstrar como o Estado moderno exerce a função de complementação numa íntima relação de dependência ontológica à totalidade social. Procuraremos, ao mesmo tempo, evidenciar que o Estado, nos marcos da sociabilidade burguesa, atende as necessidades reprodutivas do sistema do capital através de uma ação corretiva compatível com os parâmetros e limites estruturais que lhe são imanentes. Trata-se de explicitar, aqui, com base em Marx e Mészáros, a relação de complementariedade exercida pelo Estado no interior do sistema sociometabólico do capital, pois este "é o complemento perfeito das exigências internas desse sistema [...] antagonicamente estruturado" (MÉSZÁROS, 2002, p. 122).

Trazemos à discussão um tema que, em que pese não ser inexplorado, continua relevante para o enfrentamento dos problemas desafiadores que se consolidam objetivamente na contemporaneidade, sobretudo no que diz respeito ao desaguadouro do futuro da humanidade: $\mathrm{o}$ alcance ao socialismo ou a continuidade da barbárie constantemente aguçada nas desumanidades produzidas pelo capitalismo globalmente constituído. Em primeiro lugar, porque diante das variadas vertentes que teorizam sobre o Estado reafirma-se uma abordagem não hegemônica, no interior da tradição marxista, que vai ao contrafluxo das tendências predominantes que vigoram na academia. Em segundo, não menos importante e decisivo, porque o momento contrarrevolucionário que a humanidade encontrou-se mergulhada nos últimos cinquenta anos tende a se constituir como o solo fértil para o surgimento de teorias que buscam afirmar a perenidade dessa esfera político-administrativa. Nesse contexto, retomar o exame acerca dos fundamentos ontológicos do Estado moderno, à luz dos pressupostos marxianos, de modo a demonstrar sua relação com a reprodução econômica do capital, não é apenas de máxima importância, como ainda de extrema atualidade.

\section{Aspectos gerais acerca da especificidade do Estado no interior do sistema sociometabólico do capital}

No universo da ontologia marxiana, é possível afirmar que o Estado responde a uma necessidade social posta pelas sociedades de classes. Nascido da sociedade, num movimento de ininterrupta sociabilização desta última, o Estado é um atributo da vida social que tem por base a divisão hierárquica do trabalho e a propriedade privada. Surge a partir do momento em que as sociedades vão se tornando cada vez mais internamente heterogêneas, ao passo que os antagonismos sociais, que surgem pelo trâmite das mediações econômicas, passam a fazer parte da vida cotidiana. A partir daí, os indivíduos, ante a complexificação das relações que brota dos componentes entre si heterogêneos do edifício social e de seu desenvolvimento, constantemente geram diferentes modos de reagir às exigências que são postas pela vida em sociedade. Por isso, esse complexo social tem sua função desempenhada num determinado contexto histórico para assegurar as condições mínimas, pela introdução da violência na vida cotidiana, de reprodução da sociedade erguida pela divisão de classes, garantindo o nível de generidade em si alcançado por determinada sociabilidade que lhe é correspondente.

Em sua modalidade moderna, a ação do Estado está estreitamente determinada pelas necessidades do sistema reprodutivo do capital. Por via de um movimento em si puramente causal, constata-se historicamente que "O capital chegou à dominância no reino da produção material paralelamente ao desenvolvimento das práticas totalizadoras que dão forma ao Estado Moderno" (MÉSZÁROS, 2002, p. 106-107). Esta é uma exigência absoluta que se destina a assegurar e proteger permanentemente a produtividade desse sistema específico. Sua ação regulatória se materializa enquanto estrutura de comando político totalizadora integrante da sociedade burguesa. Ora, sendo integrante dessa totalidade a especificidade da sua ação só pode ser compreendida levando em consideração tal característica substantivamente decisiva.

Cumpre ressaltar, aqui, que a formação do Estado moderno é demarcada desde o período denominado por Marx (1988) de "acumulação primitiva" do capital, fase que compõe a pré-histórica do modo de produção capitalista; e tem sua consolidação com o ciclo das revoluçães burguesas ocorridas entre os séculos 17 e 19, onde a burguesia chega ao poder graças ao amadurecimento econômico e social que convergiu para seu poderio. 
À força das novas ideias, num sentido de total libertação, a burguesia aspirava, à época, à tomada de poder e à instauração de sua forma de vida específica (capitalista), pois estava cônscia de que, posteriormente, ser-lhe-ia conferida a posição de classe econômica e politicamente dominante na sociedade. Empenhou-se, então, para atingir esse fim, "em capturar o Estado porque, desse modo, [teria] em suas mãos, finalmente, o supremo poder coercitivo da sociedade e [poderia] usá-lo para os seus próprios fins" (LASKI, 1973, p. 18). Acrescente-se a isso que o revolucionamento operado com a Revolução Francesa de 1789, ao destruir as estruturas feudais e proclamar a liberdade econômica, desbastou o terreno para o capitalismo e teve como um dos momentos cruciais a formação do Estado moderno pertencente à materialidade do sistema do capital. Esse é o movimento histórico quando a burguesia mostrou seu caráter revolucionário ao remover os obstáculos que impediam o desenvolvimento burguês impostos pela nobreza feudal, classe privilegiada da sociedade feudal que detinha o poder de linhagem e a riqueza imobiliária, e pelo Estado Absolutista.

Movida pela necessidade de centralizar a política, esta classe reunia os pressupostos objetivos - resultantes, conforme afirma Soboul (1981, p. 9), do "coroamento de uma longa evolução econômica e social que fez da burguesia a senhora do mundo" - para apresentar-se como "representante universal" dos interesses de todos a partir de uma proposta de projeto global ${ }^{1}$ para a sociedade. Aglutinou em torno de si aqueles que, sublevando-se contra a nobreza e contra a sociedade feudal em declínio, aspiravam ao alcance de uma sociedade mais igualitária, onde todos fossem reconhecidos igualmente perante a lei. Contudo, ao completar a dominação política, evidencia-se que sua "representação universal" é uma representação alienada da totalidade social e impossível de ser objetivada pela sua própria natureza classista.

Sem dúvida, apesar dos aspectos positivos que guiaram seu levante revolucionário, esta classe apresenta um projeto limitado. Do tom revolucionário, a burguesia decai para o desejo de conservação da ordem por ela erguida em conjunto com as massas populares francesas. Constitui-se, por parte da burguesia, uma forma de governo voltada apenas para seus interesses específicos, dando cobertura singularmente às suas necessidades e não às necessidades de toda a nação; como assim propusera revolucionariamente. O que parecia estar voltado para todo o povo materializa-se, em seu funcionamento prático, nos interesses exclusivos de dominação dessa classe. De modo peculiar, decorre dessa ação um profundo conservadorismo: a burguesia reservara ciumentamente para si os valores libertários da revolução de 1789, consagrando suas conquistas de modo a excluir as massas populares da partilha da riqueza socialmente produzida. Por isso, a forma de Estado por ela erguida é, "por seu turno, apenas a organização que a sociedade burguesa a si própria deu para manter de pé as condições exteriores gerais do modo de produção capitalista" (ENGELS, 1974, p. 93).

Nos marcos do capitalismo, o Estado, ao moldar as manifestações reprodutivas do sistema do capital, atua de modo a proclamar todos os indivíduos como livres e iguais. Independente da substância da sua personalidade, eles são sujeitos dos mesmos direitos e regidos pelas mesmas leis; são, consequentemente, desvinculados da sua condição de classe. Neste sentido, apesar das diferenças estruturais que opõem e confrontam capital e trabalho, perante o Estado, tanto o capitalista - que tem a propriedade do capital -, quanto o trabalhador proprietário da força de trabalho - são juridicamente igualados à condição de cidadão.

Indubitavelmente, consolidado o novo modo de dominação de classe, também surgiu uma fragmentação da posição social do trabalhador. Por via de um violento processo histórico, inscrito nos anais da humanidade com "traços de sangue e fogo" (MARX, 1988, p. 252), e da revolução política operada pela burguesia, o servo feudal se converte em personagens diferentes. Por um lado, transforma-se no indivíduo do mercado e da propriedade privada sob a regência do capital; por outro, aparece, na sua vida política e coletiva, enquanto cidadão. Sob esse prisma, "a sociedade é vista [pelo Estado e pela burguesia] como uma massa de cidadãos individuais e, assim, a administração se reduziria a administrar a estes cidadãos de maneira justa e eficiente" (HOLLOWAY, 1982, p. 26).

Vale lembrar, nesse contexto, que a ação do Estado não se desprende desse horizonte ilusoriamente justo e igualitário. É ilusório porque o reconhecimento da igualdade entre os cidadãos, tomado para si por parte do Estado, demonstra seu esgotamento no campo da formalidade jurídica, "na abstração de um individualismo social igualitário" (SOBOUL, 1981, p. 166). Vale, também, lembrar que se promulga pelo aparato legal a igualdade entre os homens, reafirmando, no plano real, a desigualdade entre as classes, entre opressores e oprimidos ao ocultar a divisão da sociedade em classes antagônicas. Tratando como iguais os membros de classes sociais que não só são desiguais, assim como, inclusive, antagônicos, o conceito de cidadania "oculta esse antagonismo (a luta de classes) que é a única base para uma transição a uma sociedade na qual desaparece da realidade as desigualdades e os antagonismos, e não só das mentes dos ricos e poderosos" (HOLLOWAY, 1982, p. 26-27).

Particularmente com relação à natureza da ação estatal, esta exprime seu caráter limitado à ordem burguesa, reconhecendo e legitimando apenas as demandas que não põem em xeque a propriedade privada moderna, a organização hierárquica das classes e que garantam, de modo eficaz, a acumulação privada da 
mais-valia. E isso não poderia ser diferente já que a ação organizada do Estado, movida pelo intelecto político, é incapaz de compreender a raiz dos males sociais e atender as demandas reais dos indivíduos, que passam a se constituir em demandas de classe, pelo simples fato de sua própria natureza política. Desse modo, "O intelecto político é político exatamente na medida em que pensa dentro dos limites da política" (MARX, 1995, p. 81), desprezando a determinação da base material.

Marx (1995, p. 79), referindo-se ao Estado moderno, demonstra a incapacidade deste compreender os fundamentos dos problemas sociais imanentes à lógica sociorreprodutiva do capital. O autor salienta que a base causal dos males sociais é sempre concebida pelo universo burguês, e por sua forma de Estado correspondente, ora como "um defeito de administração e de assistência" ora como culpa dos indivíduos particulares que passam a ser culpabilizados por sua condição de miserabilidade social, pagando, barbaramente, o preço de sua pobreza. Por sua vez, a justificação do pauperismo, expresso na desigualdade inerente à organização vigente dessa formação socioeconômica que se traduz na valorização crescente do capital e no aumento significativo da miséria relativa do trabalhador, é procurada em leis da natureza, pois "o Estado jamais encontrará no 'Estado e na organização da sociedade' o fundamento dos males sociais":

Por isso, o Estado não pode acreditar na impotência interior da sua administração, isto é, de si mesmo. Ele pode descobrir apenas defeitos formais, casuais, da mesma, e tentar remediá-los. Se tais modificações são infrutíferas, então o mal social é uma imperfeição natural, independente do homem, uma lei de Deus, ou então a vontade dos indivíduos particulares é por demais corrupta para compreender aos bons objetivos da administração (MARX, 1995, p. 81).

O Estado não pode reconhecer que o capitalismo vai se instaurando em meio às relações sociais produzindo riqueza e pobreza em larga escala. Não assume que essa é a lei absoluta geral da acumulação capitalista, ao preço de explicitar sua função e por em xeque sua própria vitalidade. Disto resulta que é de sua natureza não evidenciar que o fundamento que rege a natureza do capital é a incessante busca pelo lucro. Essa é a lógica da sociedade regida pelo capital que é sempre obscurecida pela justificação do Estado e de seu aparato burocrático. O Estado, concomitante à reprodução ampliada da dominação, recria formas mistificadas que encobrem a exploração capitalista; onde esta última passa a ser apresentada como sendo algo normal, destituída de conflitos e contradições que repousam sob a base da propriedade privada moderna. Todavia, isso não acontece de maneira arbitrária, mas sempre determinada pelas relações materiais de produção que o edifica, já que, como afirma Marx (2009, p. 191): "o poder político é o resumo oficial do antagonismo na sociedade civil".

A superestrutura jurídica e política do sistema do capital, através da liberdade jurídico-legal, legitima a desigualdade social e o pauperismo nos seus níveis mais alienantes. Por isso, "quando o Estado admite a existência de problemas sociais, procura-os em leis da natureza, ou na vida privada, que é independente dele, ou na ineficiência da administração, que depende dele" (MARX, 1995, p. 59). Decorrente dessa incapacidade de compreender os fundamentos dos problemas sociais revela-se a natureza paliativa da intervenção estatal, expressa na sua impossibilidade de resolver, a ponto de superar, os problemas sociais. Resolvê-los implicaria, por conseguinte, a superação da plêiade que sustenta os antagonismos sociais reinantes no âmbito da sociedade civil e que são resultantes dos interesses irreconciliáveis das classes.

Sobre este aspecto da natureza paliativa da ação do Estado, Marx (1995, p. 80) afirma que sua ação não se orienta para a eliminação dos males, mas, contrariamente, volta-se para o disciplinamento dos problemas sociais. Sua ação restringe-se às medidas administrativas, gerenciando cotidianamente as condições de dominação necessárias à exploração dos trabalhadores pela classe capitalista, "porque a administração é a atividade organizadora do Estado"; é o mecanismo que o Estado tem de atuação e de enfrentamento das problemáticas sociais que marcam a sociedade capitalista, e que se não forem administradas ameaçam a vitalidade reprodutiva do capital.

Isso nos permite afirmar, com base nesse autor, que a ação do Estado tem sempre um caráter limitado e é determinada pelas necessidades de reprodução da base material. Vistas as coisas nesse nível, por sua própria natureza regulatória a ação do Estado restringe-se, conforme Marx (1995, p. 81), a uma atividade "formal", pois não atende as necessidades concretas de reprodução dos indivíduos; e "negativa", já que não resolve as problemáticas que emanam da natureza desigual da sociedade e que são atravessas por antagonismos sociais que dela emanam. É assim que: "Quanto mais poderoso é o Estado e, portanto, quanto mais político é um país, tanto menos está disposto a procurar no princípio do Estado [...], o fundamento dos males sociais e a compreender-lhes o princípio gera".

Em tudo isso vem à luz um fato ontológico fundamental: a burguesia criou uma ordem social fundada nos seus princípios de classe de tal modo que a centralização da política sob seu domínio se constitui enquanto um 
mecanismo de subordinar os trabalhadores aos seus ditames classistas. Portanto, por ser o Estado representante dos interesses da burguesia, o Estado moderno, compondo a materialidade do sistema do capital, se articula na estrutura da ordem sociometabólica capitalista. São, em última instância, o nível e a dinâmica de desenvolvimento do sistema de reprodução capitalista - buscando manter sua lógica: orientado pela acumulação e pela expansão (MÉSZÁROS, 2002, p. 100) - e as necessidades particulares da classe burguesa que definem o que deve ser feito na esfera da administração.

Uma vez traçados os delineamentos fundamentais, ainda que de forma breve e introdutória, que situam objetivamente a especificidade do Estado no interior do sistema sóciorreprodutivo do capital, podemos agora analisar outro ponto de entendimento acerca do Estado moderno. Trata-se da função de complementariedade deste complexo social à reprodução do capital, já que, como salienta Holloway (1982, p. 29), "a exploração capitalista e o Estado, surgem paralelamente como formas complementares de um novo modo de dominação". É sobre essa função que nos debruçamos no item que se segue.

\section{O sistema do capital e a função de complementariedade exercida pelo Estado}

Já aludimos anteriormente, em alguma medida, que a formação do Estado Moderno, transiente ao capitalismo, cumpre uma "exigência absoluta" posta pelo sistema sociometabólico de reprodução do capital e, portanto, constitui-se como parte integrante deste, emergindo "com a mesma inexorabilidade que caracteriza a triunfante difusão das estruturas econômicas do capital, complementando-o na forma de estrutura totalizadora de comando político do capital" (MÉSZÁROS, 2002, p. 106). Diante dessa determinação objetiva, apreendese que a confluência e as múltiplas determinações de reciprocidade dialética entre esses dois complexos centrais - Estado e capital - demonstram que, enquanto modo de controle singular, o capital não pode funcionar, sob a base do seu imperativo estrutural, sem uma estrutura de comando política adequada que vai até onde a ação corretiva ajusta-se aos últimos limites sociometabólicos imanentes ao capital. Do mesmo modo, o Estado moderno, imensamente "inchado" por novas profissões e pela burocracia excessiva que lhe corporifica, "em si é totalmente inconcebível sem o capital como função sociometabólica".

Para esse estudo, o efeito mais importante dessa constatação ontológica é o entendimento de que independente da forma por ele assumido no desenvolvimento histórico - imperial, democrática, constitucional, ditatorial -, o Estado moderno só se torna inteligível no interior das relações sociais que o demanda e para cuja reprodução contribui, seja por mediações mais ricas e complexas ou ainda por mediações mais simples, sendo, portanto, uma instância político-administrativa, per excellence, capitalista. Este é um produto socialmente construído de que se vale a burguesia para se organizar como classe politicamente dominante e imperiosamente exercer seu domínio global sobre o conjunto da sociedade, já que, como afirmam Marx e Engels (1993, p. 72), a classe que tem a força-material, isto é, é detentora dos meios de produção e que se apropria da riqueza socialmente produzida, para consolidar a posição de classe dominante, legitimando e reproduzindo a ordem social vigente, deve possuir também a força espiritual.

Levando em consideração essa determinação estrutural, de fato, o que nos interessa, agora, é demonstrar a função de complementação exercida pelo Estado nos marcos do sistema do capital sobre seus microcosmos produtivos materiais centrífugos. Assim sendo, cabe-nos perguntar: como se materializa essa função em consonância com os parâmetros que lhes são imanentes? Para responder essa indagação, é fundamental, antes de mais nada, assinalarmos algumas características particulares do modo de controle sociometabólico do capital para dilucidar a função de complementação do Estado moderno à sua reprodução econômica.

Como se sabe, a partir da ótica marxiana, o capital é uma relação social dominante gestada umbilicalmente no interior do feudalismo, na ultrapassagem de limites econômico-sociais peculiares às sociedades precedentes, e ainda, na separação dos trabalhadores dos seus meios de produção, por via de um processo sanguinolento, "elevando seu modo de controle metabólico ao poder da dominância absoluta como sistema global plenamente estendido" (MÉSZÁROS, 2002, p. 101). Sendo esse horizonte puramente social, o capital vai assumindo poderosamente a direção da vida dos homens ao superar e subjugar as restrições e os obstáculos que impunham a sua livre expansão, bem como ao subordinar hierarquicamente o trabalho à classe do capital personificada no processo de reprodução societal. No dinamismo próprio e particular do modo de produção capitalista, o mercado passa a constituir o elo entre as relações humanas e sociais, onde estas, por sua vez, adquirem aspecto de objetos, de coisas, ou seja, são envolvidas por um fetiche que esvazia sua historicidade.

Isso se evidencia pelo fato de que esse sistema dá a inteligibilidade de todo o processo da vida social. É uma "estrutura totalizadora de controle à qual tudo o mais, inclusive seres humanos, deve se ajustar, e assim provar sua "viabilidade produtiva", ou perecer, caso não consiga se adaptar" (MÉSZÁROS, 2002, p. 96). Esse sistema funda-se na exploração exacerbada da força de trabalho e na alienação do trabalhador mediante o que 
é produzido, ao passo em que a produção volta-se, prioritariamente, não para o atendimento das reais necessidades de reprodução dos indivíduos, mas para os trâmites do mercado, de modo a gerar mais-valia e garantir continuamente sua acumulação. É um sistema social que se ergue sob os pilares de formas de controle coercitivas que subordinam a força de trabalho às suas determinações reprodutivas e aos seus ditames.

Por essas e outras razões, "Não se pode imaginar um sistema de controle mais inexoravelmente absorvente - e, neste importante sentido, 'totalitário'- do que o sistema do capital globalmente dominante" (MÉSZÁROS, 2002, p. 96); haja vista que sua dominância "totalitária" no reino material e nas demais esferas da vida é inegável.

Nesse sistema, consolidado historicamente como "estrutura de controle singular", o objetivo dos capitalistas reduz-se à extração de mais-valia e à valorização do capital. Intensifica-se a exploração do trabalhador pela diminuição do tempo de trabalho socialmente necessário e pelo aumento da exploração do trabalho excedente. Com isso, "a sociedade toda deve se sujeitar - em todas as suas funções produtivas e distributivas - às exigências mais íntimas do modo de controle do capital estruturalmente limitado" (MÉSZÁROS, 2002, p. 99). Como reflexo dessa sujeição, tem-se a submissão à lei do capital para com aqueles que somente possuem a sua força de trabalho, o que os faz submeter-se, por intimidação, à degradação mais horrenda que é causada pela exaustão de suas mentes e corpos, tornando-se, assim, uma oferta singular para aqueles que contratualmente compram a sua força de trabalho.

Segundo Mészáros (2002, p. 97), o capital é uma "forma incontrolável de controle sociometabólico" que escapa forçosamente de um grau significativo de controle humano. Essa incontrolabilidade, inerente à sua dinâmica reprodutiva e expansionista, sinaliza que esse sistema "[...] é, na verdade, o primeiro na história que se constitui como totalizador irrecusável e irresistível, não importa quão repressiva tenha de ser a imposição de sua função totalizadora em qualquer momento e em qualquer lugar em que encontre resistência". Ter assumido essa característica de "totalizador irrecusável e irresistível" possibilita um dinamismo ao sistema do capital, tornando-o o mais competente extrator de trabalho excedente em toda a história, antes inimaginável quando comparado aos modos de controle sociometabólico que lhe antecederam no movimento da reprodução social. Mas, paradoxalmente, essa determinação interna do capital acarreta, por outro lado, uma inevitável perda de controle sobre os processos de tomada de decisão gerada pela quebra da autossuficiência.

Conforme o autor, a perda de controle é uma "deficiência fatídica" do sistema do capital. É consequência direta da separação que se consolidou historicamente entre as funções relacionadas à produção e o controle do processo de trabalho ${ }^{2}$. Dessa perda, acarretando numa "ausência de unidade", emanam os defeitos estruturais do capital, base constitutiva da reprodução contraditória do seu modo de controle particular. Diante dessa "ausência", isto é, da " "falta' de uma coesão" dos microcosmos socioeconômicos, para garantir o pleno funcionamento do sistema do capital "o Estado moderno [...] se ergue sobre a base deste metabolismo socioeconômico que a tudo engole, e o complementa de forma indispensável [...] em alguns aspectos essenciais" (MÉSZÁROS, 2002, p. 98, grifo do autor).

Nesses termos, assegurando as necessidades mais elementares da base material do sistema do capital, o Estado moderno, em seu dinamismo histórico, "passa a existir acima de tudo, para poder exercer o controle abrangente sobre as forças centrífugas insubmissas que emanam de unidades produtivas isoladas do capital, um sistema reprodutivo social antagonicamente estruturado [...]" (MÉSZÁROS, 2002, p. 107, grifos do autor).

Isto posto, comungamos com Mészáros (2002) que a partir da análise dos defeitos estruturais de controle do sistema do capital, é possível identificar como se materializa a relação prática de complementaridade do Estado moderno à sua reprodução econômica. Os defeitos estruturais do capital, sob os quais a ação do Estado se direciona, de maneira a "retificar" a ausência de unidade, são visíveis no fato de que os microcosmos que o compõe apresentam-se internamente fragmentados. Essa fragmentação, assumindo a forma de antagonismos sociais estruturalmente irreconciliáveis, explicita-se nas seguintes formas: o isolamento entre produção e controle; a produção e o consumo assumem uma interdependência; a relação opositiva estabelecida entre a produção e a circulação.

A respeito do defeito estrutural entre produção e controle, a ação do Estado apresenta-se protegendo legalmente a relação de forças que se estabelece nesse antagonismo. Possibilita as personificações do capital às condições necessárias para a dominação da força de trabalho da sociedade. É necessário acentuar a importância decisiva do Estado na reprodução das relações sociais capitalistas, na sua condição de legislador e de controlador das forças repressivas, protegendo o material alienado e os meios de produção. Essa função assumida se destina a assegurar o poder político conforme os preceitos e princípios estabelecidos pelos interesses dominantes e se mostra fundamental para a constante centralização dos meios de produção e a concentração da propriedade em poucas mãos.

Portanto, referindo-se à possibilidade de administrar a separação entre produção e controle, inseparável dos microcosmos do sistema do capital, Mészáros (2002, p. 107) advoga que: 
[...] a estrutura legal do Estado moderno é uma exigência absoluta para o exercício da tirania nos locais de trabalho. Isso se deve à capacidade do Estado de sancionar e proteger o material alienado e os meios de produção (ou seja, a propriedade radicalmente separada dos produtores) e suas personificações, os controladores individuais (rigidamente comandados pelo capital) do processo de reprodução econômica. Sem esta estrutura jurídica, até os menores "microcosmos" do sistema do capital- antagonicamente estruturado - seriam rompidos internamente pelos desacordos constantes, anulando dessa maneira sua potencial eficiência econômica.

Como nos mostra o autor, o Estado, juntamente com seu maquinário (jurídico, parlamentar, polícia, profissões), é uma "exigência absoluta", e, nesses termos, não eventual, "para evitar as repetidas perturbações que surgiriam na ausência de uma transmissão da propriedade compulsoriamente regulamentada - isto é: legalmente prejulgada e santificada - de uma geração à próxima perpetuando também a alienação do controle pelos produtores" (MÉSZÁROS, 2002, p. 108). Somando-se a esse primeiro aspecto apresentado, Mészáros (2002, p. 109) salienta que no âmbito das inter-relações conflitantes constantemente renovadas entre os microcosmos particulares, é igualmente demandável a necessidade de intervenções políticas e legais, materializadas direta ou indiretamente, sobre os conflitos próprios das unidades socioeconômicas. Com isso, o Estado, juntamente com toda sua estrutura internamente organizada, se apresenta como complemento fundamental para manter o funcionamento permanente do sistema do capital "em seu microcosmo e nas interações das unidades particulares de produção entre si, afetando intensamente tudo, desde os intercâmbios locais mais imediatos até os de nível mais mediato e abrangente".

Percebe-se que a ação corretiva do Estado sobre esse defeito estrutural ocorre sempre em consonância com a dinâmica reprodutiva específica do capital, de modo que "o Estado reforça a dualidade entre produção e controle e também a divisão hierárquico/estrutural do trabalho, de que ele próprio é uma clara manifestação" (MÉSZÁROS, 2002, p. 122). Neste sentido, apreende-se que "o Estado moderno altamente burocratizado, com toda a complexidade do seu maquinário legal e político, surge da absoluta necessidade material da ordem sociometabólica do capital" (MÉSZÁROS, 2002, p. 108), tornando-se "uma precondição essencial para a subsequente articulação de todo o conjunto".

Sobre o segundo defeito apresentado pelo sistema do capital - ruptura entre produção e consumo -, o papel totalizador do Estado moderno, juntamente com seus métodos organizacionais correspondentes, mostra-se essencial. Suas ações corretivas devem materializar-se em íntima conjunção com os imperativos do sistema do capital e "em sintonia com a dinâmica variável do processo de reprodução socioeconômico, complementando politicamente e reforçando a dominação do capital contra as forças que poderiam desafiar as imensas desigualdades na distribuição e no consu-

... o Estado moderno só se
torna inteligível no interior das
relações sociais que o demanda
e para cuja reprodução
contribui, seja por mediações
mais ricas e complexas ou
ainda por mediações mais
simples, sendo, portanto, uma
instância político-
administrativa, per excellence,
capitalista.
mo" (MÉSZÁROS, 2002, p. 110).

Assumindo essa função retificadora, o próprio Estado deve tornar-se "comprador/consumidor direto em escala sempre crescente". Em certos momentos de expansão, o sistema do capital exigiu um Estado comprador, principalmente, do complexo industrial-militar, com tudo o que este apresenta de alienação, convertendo-o, sobretudo, nos marcos do século 20, no setor mais importante da economia mundial. Por via da satisfação de "apetites em sua maioria artificiais", o Estado, na condição de consumidor, alimenta a máquina burocrática altamente alienante e o complexo militar. Se isso é fundamental para a lógica reprodutiva do capital, não é, pois, suficiente. Por isso, através de sua função política regulatória, o Estado intervém na economia estimulando a expansão desenfreada para que os trabalhadores também se tornem consumidores das mercadorias por eles produzidas.

Por via dessa intervenção, os trabalhadores são, então, convocados para compor o universo dos consumidores de produtos industrializados, intensificando os lucros capitalistas e a taxa de mais-valia para o capital. Assim, "o trabalhador como consumidor desempenha um papel de grande (ainda que muito variável ao longo da história) importância no funcionamento saudável do sistema do capital” (MÉSZÁROS, 2002, p. 110). É inevitável que além de estarem alienados à produção, os trabalhadores alienem-se, também, na esfera do 
consumo, porquanto passam a consumir mercadorias supérfluas para sua reprodução, o que contribui para a manutenção da necessidade de permanente expansão do consumo.

Outro aspecto, não menos importante e decisivo, deve ser salientado no tocante à ação do Estado sobre o antagonismo estabelecido entre produção e consumo. Cumprindo a função de consumidor, o Estado vê-se obrigado a reconhecer e garantir, ainda que subordinadamente e minimamente, algumas demandas postas pelas lutas trabalhistas, tais como: educação, saúde, habitação e serviços de seguridade social. Todavia, vale salientar que isso só é possível em determinadas circunstâncias históricas específicas, assimilando-as ao conjunto do sistema, sem, contudo, colocar em xeque as determinações vitais de reprodução do capital.

Decisivo aqui é o entendimento de que o provimento de algumas necessidades reais do conjunto social em nada põe em contratempo a vitalidade do sistema sociometabólico de reprodução do capital e, com isso, não são ameaçadoras da ordem vigente. Ao contrário, em circunstâncias históricas determinadas demandas do movimento dos trabalhadores apresentaram-se como integrantes à estrutura totalizadora do sistema. E, só por isso, podem ser concedidas de modo a contribuir decisivamente para o processo de expansão e acumulação do capital. Para exemplificarmos rapidamente, a experiência histórica do Estado de Bem-Estar Social demonstra que, a longo prazo, os ganhos obtidos pela classe trabalhadora são eliminados, uma vez que não são sustentáveis no desenvolvimento da globalização do capital.

No que diz respeito à fragmentação entre produção e circulação, componente da tríplice de defeitos estruturais do sistema do capital, o papel ativo do Estado é, conforme Mészáros (2002), indispensável para a existência e reprodução do capital enquanto sistema globalmente constituído e se consolida inseparável dos requisitos cumulativos desse sistema.

Na busca por estabelecer alguma unidade entre essa fragmentação operada no sistema do capital, a ação do Estado se expressa no imperativo de criar a circulação como ação global das estruturas internamente fragmentadas do sistema do capital, sem que haja uma ameaça à reprodução do sistema. A política totalizadora acaba por garantir o desenvolvimento necessário de um sistema internacional de subordinação e dominação, que estabelece uma "hierarquia de Estados nacionais mais ou menos, poderosos que gozem - ou padeçam - da posição a eles atribuída pela relação de forças em vigor (...) na ordem de poder do capital global” (MÉSZÁROS, 2002, p. 111). Por isso mesmo, a ação do Estado no que concerne à fragmentação entre produção e circulação, ainda que seja indispensável, só encontra um equilíbrio temporariamente definido e não uma resolução efetivamente duradoura.

Tanto a eliminação de barreiras locais ou regionais ao crescimento dos mercados como a expansão sem limites, necessidade constante do processo de acumulação do capital, são requisitos essenciais do capitalismo. No entanto, evidencia-se que, do ponto de vista do dinamismo histórico particular ao capitalismo, "as estruturas corretivas global e de comando político do sistema do capital se articulam como Estados nacionais, embora como modo de reprodução e controle sociometabólico (com seu imperativo de circulação global), seja inconcebível que tal sistema se confine a esses limites" (MÉSZÁROS, 2002, p. 111).

Para atuar sobre essa contradição, de modo a administrá-la, a única forma encontrada pelo Estado moderno é o estabelecimento de um sistema de "duplo padrão" característico por ser: "Em casa (ou seja, nos países "metropolitanos" ou "centrais" do sistema do capital global), um padrão de vida bem mais elevado para classe trabalhadora - associado à democracia liberal. Já na "periferia subdesenvolvida", tem-se "um governo maximizador da exploração, implacavelmente autoritário (e, sempre que preciso, abertamente ditatorial), exercido diretamente ou por procuração" (MÉSZAROS, 2002, p. 111).

Contudo, esse duplo padrão de hierarquia, estabelecido pelos Estados, não se destina a um aspecto "permanente do ordenamento global do sistema". Isto significa que pode haver mudanças em seu interior e que sua duração "[...] se limita às condições da ascendência histórica do sistema, enquanto expansão e a acumulação tranquilas proporcionarem a margem de lucro necessária que permita um índice de exploração relativamente favorável da força de trabalho nos países "metropolitanos", em relação às condições de existência da força de trabalho no resto do mundo" (MÉSZÁROS, 2002, p. 111).

Sob esse "duplo padrão" de tratamento movido pela ação corretiva estatal, Mészáros (2002) afirma ainda que nas últimas décadas manifestam-se duas tendências complementares que são significativas nesse aspecto. A primeira delas, afetando diretamente o rebaixamento do padrão de vida dos trabalhadores, evidencia-se na certa "equalização no índice diferencial de exploração", isto é, no progressivo aumento no grau de exploração da força de trabalho. Já a segunda tendência, paralelamente a esta equalização, emerge de seu "necessário corolário político" traduzindo-se num "crescente autoritarismo nos Estados 'metropolitanos"”, "e um desencantamento geral, perfeitamente compreensível, com a "política democrática”, que está profundamente implicada na virada autoritária do controle político nos países capitalistas avançados” (MÉSZÁROS, 2002, p. 112).

Considerando as duas tendências mencionadas, o Estado, como "agente totalizador da criação da circulação global", intervém de maneira distinta: determinadas ações são desenvolvidas no âmbito das ações internacionais de tal maneira que o Estado não busca restringir a expansão monopolista ilimitada nas suas unidades 
econômicas dominantes, atuando como um "facilitador da expansão mais monopolista possível do capital no exterior". Não obstante, outras ações são empregadas em sua política interna, atuando, necessariamente, na busca dos meios, compatíveis com a dinâmica de expansão e dominância totalitária do capital, que evitem que a "inexorável tendência à concentração e à centralização do capital leve à eliminação prematura de unidades de produção ainda viáveis".

\section{Conclusão}

Durante esse estudo, procurou-se dar alguns passos, ainda que bastante lacunares, no sentido de captar como se materializa a função de complementação desempenhada pelo Estado no interior do processo de reprodução do capital na sua totalidade. Vimos que, em sua modalidade moderna, o Estado representa o poder politicamente organizado da classe burguesa para a garantia de seus interesses hegemônicos. Vimos, ao mesmo tempo, que os capitalistas impuseram ao Estado a necessidade de desenvolver ações corretivas que passam a ser vitais para o capital enquanto mecanismo usado para estabelecer a coesão de um todo fragmentado. Foi possível apreender que sua ação limita-se a um caráter corretivo, remediador dos males sociais, sendo, por isso, um elemento coercitivo necessário para o funcionamento do capital. Seu papel vital é a garantia e a proteção das condições gerais de extração da mais-valia do trabalho excedente.

Por fim, percebe-se, com base nos autores aqui estudados, que o Estado cumpre uma função social precisa no interior da totalidade social: o Estado é uma instância que convive funcionalmente com a reprodução econômica do capital, não se autonomizando da esfera econômica; ao contrário, desta esfera é inseparável e mantém uma relação de determinação reflexiva, donde a primazia dessa relação é dada pela esfera econômica. Sob esse prisma, a ação reguladora do Estado burguês, independentemente da forma por ele assumida no desenvolvimento do capitalismo, não possui natureza revolucionária, sendo, portanto, por sua funcionalidade à reprodução da dominação de classes, impotente para alterar a sociedade civil e levar a cabo a emancipação dos indivíduos. Essa explicação põe-se como necessária para que possa ser racionalmente fundamentada a possibilidade de uma superação das amarras do capital, assim como para romper com as proposições reformistas que mascaram os verdadeiros nexos de existência do Estado na sociedade regida pelo capital.

\section{Referências}

ENGELS, F. Do socialismo utópico ao socialismo científico. Tradução de João Abel. Lisboa: Editorial Avante, 1974. (Biblioteca do marxismo-leninismo).

HOLLOWAY, J. Fundamentos teóricos para una crítica marxista de la Administração Pública. México: Instituto Nacional de Administración Pública, 1982.

LASKI, H. J. O liberalismo europeu. Tradução de Álvaro Cabral. São Paulo: Mestre Jou, 1973.

LUKÁCS, G. Realismo e existencialismo. Lisboa: Editora Arcadia, s/d.

MARX, K. O capital. V. I, Tomo II. Tradução de Regis Barbosa e Flávio R. Kothe. São Paulo: Nova Cultura, 1988. (Coleção Os Economistas).

. Glosas Críticas Marginais ao artigo “O Rei da Prússia e a Reforma Social. De um prussiano”. Revista Práxis, Belo Horizonte, MG, n. 5, p. 68-91, 1995.

Miséria da Filosofia: resposta à Filosofia da miséria do Sr. Proudhon. Tradução de José Paulo Netto. São Paulo: Expressão Popular, 2009.

MARX, K.; ENGELS, F. A ideologia alemã (Feuerbach). São Paulo: Hucitec, 1993.

MÉSZÁROS, I. Para além do capital. Tradução de Paulo Cezar Castanheira e Sérgio Lessa. São Paulo: Boitempo, 2002.

SOBOUL, A. História da Revolução Francesa. Tradução de Hélio Pólvora. Rio de Janeiro: Zahar, 1981.

\section{Notas}

1 SegundoLukács (s/d, p. 29), "São os vastos interesses gerais de uma classe, colocada sobre a cena da história mundial, objetivamente chamada a transformar no sentido do progresso o conjunto da sociedade, que recebem a sua expressão adequada nas obras da filosofia clássica".

2 No devido esclarecimento que essa separação não se aplica apenas aos trabalhadores enquanto indivíduos particulares é preciso frisar que ela atinge também os grandes capitalistas, que "têm de obedecer aos imperativos objetivos de todo o sistema, exatamente como todos os outros, ou sofrer as consequências e perder o negócio” (MÉSZÁROS, 2002, p. 98). 


\section{Fernando de Araújo Bizerra}

nando_epial@hotmail.com

Mestrando do Programa de Pós-Graduação em Serviço Social pela Universidade Federal de Alagoas (UFAL)

\section{Juliana Carla da Silva Gois}

juh-carla@hotmail.com

Mestranda do Programa de Pós-Graduação em Serviço Social pela Universidade Federal de Alagoas (UFAL)

\section{UFAL - Faculdade de Serviço Social}

Campus A. C. Simões - Av. Lourival Melo Mota, s/n, Cidade Universitária

Maceió - Alagoas - Brasil

CEP: 57072-900 